\title{
Meteoritos, dinossauros, borboletas... e também saúde
}

\author{
Meteorites, dinosaurs, butterflies... and \\ also health \\ Meteoritos, dinosaurios, mariposas... y \\ también salud
}

Sheila Maria Ferraz Mendonça de Souza 1
Claudia Rodrigues-Carvalho 2

doi: 10.1590/0102-311X00190918
Durante os muitos anos nos quais trabalhamos em pesquisa e ensino, atuamos entre duas instituições, dois monumentos, dois ícones de nossa história e da ciência que abraçamos, na interface entre as antropológicas e a saúde pública e coletiva. A primeira autora, médica e professora, encarregou-se de ensinar e produzir conhecimento sobre a saúde no passado; a segunda, arqueóloga, iniciada como aluna, avançou aos poucos para abraçar a mesma experiência acadêmica. Fizemos um longo trajeto juntas. É esse trajeto que prossegue nesta memória, que compartilhamos como participantes, por diferentes caminhos e em diferentes momentos, da História da Ciência no Brasil. Assim, ainda prosseguimos, principalmente agora ante o desastre, porque mais do que nunca é preciso prosseguir. Os castelos que compartilhamos se chamam Fundação Oswaldo Cruz (Fiocruz) e Museu Nacional.

Após anos de convívio e colaboração com pesquisadores da Escola Nacional de Saúde Pública Sergio Arouca (ENSP/Fiocruz), Sheila ingressou como médica no Doutorado desta Escola, passando logo depois a fazer parte do quadro de pesquisadores da instituição. Somando e contribuindo, aproximou ainda mais da Fiocruz o florescente segmento das pesquisas antropológicas e arqueológicas sobre saúde. Na qualidade de arqueóloga, Claudia fez na Escola seu Mestrado e Doutorado, no Programa de Pós-graduação em Saúde Pública, contribuindo efetivamente para a aproximação metodológica e conceitual entre as Ciências da Saúde e da Antropologia com efetivos resultados de suas pesquisas sobre a saúde no passado. Diferentes pontos de partida, chegadas convergentes. Em comum, pesquisadoras, professoras, gestoras em prol daqueles icônicos castelos. Claudia dirigiu o Museu Nacional nos últimos oito anos, antes do desastre.

Muitos talvez se perguntem o que existe entre a Fiocruz e o Museu de tão próximo, a ponto de o sinistro nos mobilizar, nos afetar, nos emocionar até ficarmos paralisados, deprimidos, adoecidos. O que escrevemos aqui ajuda a compreender porque as duas instituições, castelos de saber e ciência, notáveis, apesar de continuamente ameaçados pelo desamparo que historicamente golpeia a ciência e a saúde no Brasil, são irmãs neste momento.

As relações entre o Museu e a maioria de nós, que hoje fazemos parte da comunidade ENSP, começou certamente na infância. Museu-lugar das crianças da cidade. Mas disso certamente não é preciso falar. Para outros, pesquisadores da Fiocruz e da ENSP, vai além.
1 Escola Nacional de Saúde Pública Sergio Arouca, Fundação Oswaldo Cruz, Rio de Janeiro, Brasil. 2 Museu Nacional, Universidade Federal do Rio de Janeiro, Rio de Janeiro, Brasil.

\section{Correspondência}

S. M. F. Mendonça de Souza Departamento de Endemias Samuel Pessoa, Escola Nacional de Saúde Pública Sergio Arouca, Fundação Oswaldo Cruz.

Rua Leopoldo Bulhões 1480, sala 606, Rio de Janeiro, $R J$ 21041-210, Brasil. sferraz@ensp.fiocruz.br 
Naquele museu de História Natural, o quinto do mundo, cristalizaram-se muitas vocações e caminhos que levaram a carreiras nas Ciências Biológicas e da Saúde. A emoção das visitas às exposições, a participação nos eventos, o entusiasmo dos estágios, o contato com mestres e referências profissionais, a experiência nos diferentes campos de pesquisa nas duas instituições, as missões científicas compartilhadas, as caminhadas solidárias, tudo isto forjou parte de nossa força de trabalho, aqui como lá.

Para alguns, é verdade, as relações foram ainda mais profundas. Orientadores de dissertações e teses, a pesquisa nas respectivas coleções, os projetos para a descoberta de novas dimensões da saúde, as orientações de alunos nos respectivos programas de pós-graduação, incansáveis discussões nos eventos, bancas, publicações, exposições, enfim, cada pequena vitória da rotina acadêmica. Décadas de vivências em verdadeiras redes colaborativas da ciência. Sim, para a ENSP, como também para outras unidades da Fiocruz, o Museu representou parceria prolongada e importante na produção do conhecimento sobre saúde e na preparação e formação de profissionais, suporte científico e projetos de futuro com potencialidades quase infinitas de trabalho continuado e produtivo voltado para o conhecimento sobre a saúde.

Lugar central das pesquisas antropológicas, zoológicas e botânicas de excelência, entre outras, o Museu desempenhou um papel importante na produção dos conhecimentos sobre saúde, tanto como interlocutor, fonte de materiais e acervos como produtor direto de conhecimento por intermédio de seus formados e pesquisadores. No Instituto Oswaldo Cruz (IOC), na Casa de Oswaldo Cruz (COC), assim como na ENSP, talvez as unidades da Fiocruz mais intensamente envolvidas com os diferentes departamentos do Museu Nacional, são incontáveis as parcerias que por mais de um século foram estabelecidas e continuavam vibrando na produção acadêmica de nosso campo multidisciplinar e complexo.

Compartilhando conhecimentos biológicos, zoológicos, históricos, antropológicos e epidemiológicos, muitos profissionais interessados na História das Doenças e da Saúde, na História e Sociologia das Ciências, na Genética, no comportamento humano e suas consequências, a ENSP, por meio de seus diferentes pesquisadores e alunos, bebeu e ainda bebe na fonte do Museu. Para nossa tristeza, muitos trabalhos em andamento estão hoje mutilados, como os que as autoras desta memória realizavam em colaboração internacional com a Universidade de Nova York (Estados Unidos). Correm risco de descontinuidade, ou pelo menos perda severa. Como esse, diversos trabalhos, ao longo de décadas, atestaram a vitalidade das colaborações interinstitucionais ENSP/Museu Nacional. Outro trabalho recente, aceito na PLoS One poucos dias antes do incêndio, havia sido realizado com base na colaboração entre IOC/ENSP/Museu Nacional, evidenciando cepas de microbactérias causadoras de tuberculose em esqueletos humanos antigos 1 que hoje estão perdidos. A pesquisa de vários estudantes nos programas de pós-graduação conjugou interesses científicos, saberes e acervos em ambas as instituições. Um exemplo é a Dissertação de Mestrado defendida em 1998 no Programa de Saúde Pública da ENSP que versou sobre leishmaniose e utilizou roedores silvestres de uma coleção daquele Museu 2 , acervo este que felizmente está salvo em prédio anexo. Outros exemplos poderiam ser relacionados.

Na década de 1980, estudos de paleoparasitologia já eram desenvolvidos em cooperação com equipes do Departamento de Antropologia do Museu Nacional. A partir da década de 1990, a troca de amostras e a presença de profissionais de ambas as instituições foram intensificadas e já incluíam cursos de especialização oferecidos na ENSP, contribuindo para a formação de alunos, técnicos, estagiários e pesquisadores/professores do Museu, reunindo aqueles interesses à capacidade formativa da ENSP, e reforçando os laços na construção de um grande grupo colaborativo devotado ao estudo dos processos de saúde e doença no passado.

Outras iniciativas conjuntas visando à extroversão de conhecimentos poderiam ser lembradas, já que desde a década de 1990 exposições, seminários e eventos científicos também foram realizados em ampla colaboração, na qual inclui a COC, o Museu da Vida, o IOC e outras unidades da Fiocruz. Esse trabalho conjunto por décadas aproximou nossas equipes, integrou nossa produção, cruzou os destinos de nossos alunos e dos profissionais que formamos.

$\mathrm{Na}$ ENSP, além das afinidades naturais decorrentes das raízes da Saúde Pública, fortemente plantadas nas Ciências Biomédicas, houve um crescimento significativo no campo da Paleopatologia e da Paleoepidemiologia, já que os estudos da saúde no passado, iniciados na década de 1980 com o Museu, desdobraram-se em produção científica crescente, formação sistemática de profissionais em nossos cursos de stricto e lato sensu, e no reerguimento de um setor importante do Museu, ameaçado pela política de restrição de vagas para a Universidade Federal do Rio de Janeiro (UFRJ), especial- 
mente intensa até meados da última década do século XX. Graças a uma prolongada e permanente colaboração que envolveu cessões temporárias de servidores, política de formação e aproveitamento de recursos humanos, captação de recursos e trabalho conjunto de profissionais, realização de projetos em colaboração e fortalecimento de equipes, grupos de pesquisa da ENSP e do Museu, liderados por Adauto Araújo, Luiz Fernando Ferreira, Ricardo Ventura Santos e Carlos Coimbra Jr., além das autoras, mantiveram-se coesos em torno de um projeto de fortalecimento do Departamento de Antropologia, principalmente voltado para os setores de Antropologia Biológica e de Arqueologia, hoje ocupando posição destacada naquela instituição. Outros nomes podem ser lembrados em nossa Escola e no Museu.

Os primeiros estudos em paleoparasitologia, na década de 1980, foram realizados com base em exemplares da coleção arqueológica que provavelmente foram destruídos no incêndio. O corpo de mulher naturalmente mumificado, proveniente de Rio Novo, Minas Gerais, doado ao Museu na época do Império, foi tema de pesquisa e publicação por colegas da ENSP 3 . Desdobrando a parceria então iniciada, o próprio campus da Fiocruz foi motivo de pesquisa arqueológica pela equipe do Museu Nacional, que aqui encontrou sinais de ocupaçoes pré-histórica, além de depósitos históricos datados dos primórdios do IOC. Desde então, e principalmente a partir dos últimos 15 anos, dezenas de trabalhos em colaboração foram publicados, além das comunicações realizadas em congressos científicos. A produção científica, que inclui alguns exemplos nesta memória 4,5,6,7. Teses e dissertações sobre materiais dos acervos do Museu, tais como a Coleção do Sambaqui de Cabeçuda, as coleções anatômicas, as coleções de sambaquis do Rio de Janeiro, a coleção de Lagoa Santa, as coleções de Guajajara e de Botocudo, foram também realizadas. Alguns estudos especialmente destacados abordaram a notável coleção Egípcia, permitindo que por meio de tomografias produzidas em cooperação com o Centro de Diagnóstico por Imagem (CDPI), fosse produzido um acervo de mais de 8 mil imagens, material farto a ser trabalhado por muito tempo ainda.

No Museu encontram-se hoje professores e técnicos, com grande produtividade em pesquisa, alguns dos Doutores e Mestres, egressos do Programa de Saúde Pública e sempre atentos às trocas e colaborações em ensino e pesquisa. Da mesma forma, pesquisadores de ambas as instituições participam de orientações, bancas, desenvolvem projetos e atividades educativas em conjunto.

Outros grupos de pesquisa, como os dedicados ao estudo das doenças transmitidas por vetores e os dedicados aos estudos de saúde e grupos indígenas do Brasil, tiveram sua formação e incorporação de profissionais, tanto lá quanto aqui, fortemente apoiados nesta parceria histórica entre Museu e Saúde Pública. Profissionais notórios e produtivos, de grande reputação internacional, que hoje atuam em ambas as instituições tiveram sua formação e experiência profissional anterior ligada a ambos. Assim, Reinaldo Souza-Santos, Carlos Coimbra Jr., Ricardo Ventura Santos, além desta autora, colaboraram temporariamente como profissionais em ambas as casas. Hoje, Ricardo Santos ainda atua como professor e pesquisador nas duas instituições. Trabalhos e colaboração entre diferentes profissionais dos Departamentos de Planejamento e Políticas de Saúde, de Ciências Sociais, de Ciências Biológicas, de Saneamento em Saúde e o Museu Nacional certamente poderão somar aos muitos a serem contabilizados em nossa história. Convites frequentes para bancas acadêmicas têm sido uma rotina entre as áreas de Saúde, Antropologia, Arqueologia, Ciências Sociais, Zoologia, Epidemiologia, entre outras.

O incêndio no Palácio, prédio principal do Museu Nacional, afetou diretamente as coleções antropológicas, entomológicas, geológicas, paleontológicas e o acervo histórico. Ainda que seja possível recuperar alguns elementos desse valioso acervo, muitas serão as perdas irreparáveis. O que o fogo não destruiu pode ter se tornado inviável para algumas pesquisas, especialmente aquelas que dependem de elementos orgânicos. Nesse contexto, após os procedimentos de resgate há que se debruçar sobre o acervo e investigar seu (novo) potencial informativo. Igualmente importante, será buscar entre os colaboradores e pesquisadores que passaram pelo Museu, todos os dados e imagens sobre o acervo que possam ser disponibilizados.

No que diz respeito às coleções de antropologia biológica, por exemplo, será importante recuperar todas as informações disponíveis e associá-las aos dados do Tombo do setor (cuja cópia digital foi preservada do incêndio), de modo que as pesquisas e a coleção permaneçam na memória da instituição e sejam disponibilizadas a todos, ainda que virtualmente.

Nesse sentido, o desafio é triplo: reconstituir o que for possível das coleções incendiadas (materialmente ou não); dar continuidade às pesquisas; e manter a incorporação de novos elementos ao 
acervo. A despeito da dimensão desse desafio, parcerias como as estabelecidas entre o Museu e as diferentes unidades da Fiocruz dão fôlego à empreitada e força para o recomeço. Precisamos voltar sobre nossa história conjunta e recuperar dados e informações de hoje podem estar dispersas ao longo desta trajetória comum. Mas, sobretudo, é preciso continuar este trajeto, que vem sendo traçado há décadas, de colaboração, respeito, solidariedade, fé na ciência. O Museu vive!

No Museu dos meteoritos, dinossauros e borboletas também havia Saúde Pública e Coletiva. Perseveramos nesta luta, que além do mais não é só nossa. Somos Fiocruz. Somos ENSP. Somos Museu Nacional. Somos UFRJ. Somos o Estado Brasileiro!

\section{Colaboradores}

S. M. F. Mendonça de Souza contribuiu com a redação de parágrafos, revisão final e referências bibliográficas. C. Rodrigues-Carvalho contribuiu com a redação de diferentes partes do texto, revisão e ajustes finais e referências bibliográficas.

\section{Referências}

1. Guedes L, Jaeger LH, Liryo A, Rodrigues-Carvalho C, Souza S. Tuberculosis in post-contact Native Americans of Brazil: paleopathological and paleogenetic evidence from the Tenetehara-Guajajara. PLoS One 2018; 13:e202394.

2. Costa LMC. Leishmaniose tegumentar americana: uso de técnicas da biologia molecular (PCR) no diagnóstico de infecção natural em roedores de coleção do Museu Nacional UFRJ [Dissertação de Mestrado]. Rio de Janeiro: Escola Nacional de Saúde Pública Sergio Arouca, Fundação Oswaldo Cruz; 1998.

3. Beltrão MC, Lima TA. Mumificações naturais na pré-história brasileira: um estudo de caso. Revista de Arqueologia 1986; 3:3-39.

4. Bastos MQ, Santos RV, Souza S, RodriguesCarvalho C, Tykot RH, Cook DC, et al. Isotopic study of geographic origins and diet of enslaved Africans buried in two Brazilian cemeteries. J Archaeol Sci 2016; 70:82-90.

5. Cook DC, Bastos MQR, Lopes C, Souza S, Santos RV. Pretos Novos: evidence for african oral hygiene practices in Brazil, 1769-1830. Int J Osteoarcheol 2012; 25:238-44.

6. Couri MS, Cunha AM, Souza S, Cunha E, Pinheiro J. Diptera Brachycera found inside the esophagus of a mummified adult male from the early XIX century, Lisbon, Portugal. Mem Inst Oswaldo Cruz 2008; 103:211-3.

7. Souza S, Reinhard KJ, Lessa A. Cranial deformation as the cause of death for a child from the Chillon river valley, Peru. Chungara - Revista de Antropología Chilena 2008; 40:41-53. 